\title{
The influence of the tool base on the formation of stresses in wear-resistant coatings in the cutting process
}

\author{
Aleksey Chikhranov ${ }^{1,2, *}$, Vladimir Tabakov ${ }^{1}$, and Olga Nazarova $^{2}$ \\ ${ }^{1}$ Federal State Budgetary Educational Institution of Higher Education Ulyanovsk State Technical \\ University, Ulyanovsk, Russian Federation \\ ${ }^{2}$ Federal State Budgetary Educational Institution of Higher Education Ulyanovsk Institute of Civil \\ Aviation named after Chief Marshal of Aviation B.P. Bugaev, Ulyanovsk, Russian Federation
}

\begin{abstract}
The results of studies of the influence of the material of the tool base on the formation of stresses in wear-resistant coatings of various compositions are presented. It is shown that the stresses in the coating during the cutting process depend on the properties of the material of the tool base and the composition of the coatings. The stresses change in the coatings during the cutting process is analyzed. It is shown that the use of coatings with high compressive stresses makes it possible to increase the period of resistance of plates made of hard alloy and high-speed steel.
\end{abstract}

\section{Introduction}

Wear-resistant coatings considerably increase the efficiency of the cutting tool [1-6]. The effectiveness of using such coatings depends on both the physical and mechanical properties of the coating materials and the tool base, and on the conditions for the interaction of the cutting tool with the material being processed. All this causes the presence and change in time of internal stresses in the coating material [7-10]. Thus, the determination of both the components of internal stresses, depending on various factors, and the total stress values in the coating material, is the basis for evaluating the efficiency of the cutting tool with coatings. The purpose of this work is to study the influence of the instrumental base on the stress state of wear-resistant coatings in the process of cutting.

\section{Methodology of Experiment}

Wear-resistant coatings with a thickness of $5 \mathrm{mcm}$ TiN, TiZrN, TiZrAlN, TiZrCrN were applied to the Bulat- 6 machine installation on plates made of hard MK8 alloy and highspeed steel P6M5K5. The chemical composition was selected according to the recommendations of [10]. Residual compressive stresses $\sigma_{0}$ were investigated on the ДРОН-3М diffractometer according to the method of [11], the Young's modulus $E$ was determined by the method of [12].

* Corresponding author: chihranov@mail.ru 
Determination of contact characteristics - specific loads and temperatures at the front and rear surfaces of the cutting tool - was carried out according to the methods described in $[13,14]$. Calculations were carried out based on the experimentally obtained data of the cutting process: the lengths of the contact of the chips with the front surface, which make up the cutting forces; coefficient of chip shortening. These indicators were obtained during turning processing of blanks made of structural steel 30ХГСА with cutters with replaceable plates made of hard alloy MK8 at the following conditions: speed $V=180 \mathrm{~m} / \mathrm{min}$, feed $S=0.15 \mathrm{~mm} / \mathrm{rot}$, depth $t=0.5 \mathrm{~mm}$, and from high-speed steel P6M5K5 at the mode: $V=55$ $\mathrm{m} / \mathrm{min}, S=0.3 \mathrm{~mm} / \mathrm{rot}, t=0.75 \mathrm{~mm}$. The evaluation of the thermal and stressed states in the cutting tool wedge was carried out by numerical methods of calculations using the ANSYS software package. The efficiency of the cutting tool was evaluated by the period of durability during turning processing of blanks from steel 30ХГСА.

\section{Research Results and Discussion}

The main stresses leading to the destruction of wear-resistant thin coatings are stresses acting parallel to the "coating-tool base" interface $[10,15,16]$. These normal stresses can be represented as the sum of the following terms:

$$
\sigma=\sigma_{c}+\sigma_{\Sigma}=\sigma_{c}+\sigma_{l}+\sigma_{\text {therm }}+\sigma_{\text {res }}
$$

where $\sigma_{c}$ are the time-varying stresses resulting from the creep of the material of the tool base; $\sigma_{\Sigma}$ are the stresses constant in time and equal to the sum of the stresses arising in the process of cutting $\sigma_{1}$, the thermal stresses $\sigma_{\text {therm }}$ arising in the coating during cutting from the uneven distribution of temperature and the residual stress $\sigma_{\text {res }}$, formed during coating.

Stresses $\sigma_{1}$ can be determined proceeding from the compatibility condition of the deformation of the coating and the tool base, taking into account the $\sigma_{\text {therm }}$ stresses acting on an instrumental basis, according to the formula

$$
\sigma_{1}=E \sigma_{x} / E_{0}
$$

where $E$ and $E_{0}$ are the Young's modulus of the coating and the tool base, respectively; $\sigma_{x}$ are the stresses acting in the tool base in a direction parallel to the front surface.

Thermal stresses arising in the coating as a result of thermal expansion of the coating and the tool base in the cutting process can be calculated by the formula:

$$
\sigma_{\text {therm }}=\left(\alpha_{0}-\alpha\right) E \Delta T /(1-v)
$$

where $\alpha_{0}, \alpha$ - coefficients of thermal linear expansion of the material of the tool base and coating, respectively; $\Delta T$ - the difference between the contact temperature on the front surface of the cutting tool with a coating and room temperature; $v$ is Poisson's ratio.

Using the compatibility condition for the deformation of the coating and the tool base, the stresses $\sigma_{c}$ arising in the coating due to the creep process of the material of the tool base can be written as:

$$
\sigma_{c}=E A \sigma_{x}{ }^{k} \tau^{1 / 3}
$$

where $A, k$ are coefficients that depend on the properties of the tool base and temperature $[10] ; \tau$ - tool life with coating.

It follows from expression (4) that at the initial instant of time the stresses $\sigma_{c}$ are zero.

In Fig.1, the stress distribution $\sigma_{1}, \sigma_{\text {therm }}, \sigma_{\text {res }}$ as well as the total stresses $\sigma_{\Sigma}$ in the TiZrN coating on the front surface of the cutting tool are shown as an example. 



Fig. 1. Distribution of stresses in the TiZrN coating on the front surface: $x$ - distance from the cutting edge; 1 - $\sigma_{1}, 2-\sigma_{\text {therm }}, 3-\sigma_{r e s}, 4-\sigma_{\Sigma}$, a - MK8; b - P6M5K5

It is seen that the distribution of stresses in the coating is different and depends on the instrumental basis. So for a base of a hard alloy, lower stress values $\sigma_{\text {res }}$ are observed than for a base of steel P6M5K5. Stresses $\sigma_{\text {therm }}$ for a hard alloy are compressive, while for highspeed steel they are tensile. Higher values of the stress $\sigma_{1}$ in the coating deposited on the plates of P6M5K5 are related to the difference in the Young's modules of the coating and the tool base. The difference in stresses in the coatings deposited on different tool bases allows us to conclude that more favorable conditions for the coating applied to the hard alloy.

In the process of work, the creep of the tool base causes a change in the stress state of the coatings. In Fig. 2 shows the variation of the total stresses in the TiZrN coating on the front surface of the cutting tool over time. It can be seen that the middle of the chip contact with the front surface is the most dangerous place for any tool base. Here, because of the presence of high temperatures, the creep of the tool material is most intensive, which leads to a change in the stress state of the coating. Over time, stresses in the coating pass from compressive to tensile, which subsequently leads to the destruction of the coating. Comparing the influence of the instrumental basis on the change in stresses in the coating, it should be noted that the greatest increase in stress occurs in the coatings deposited on high-speed steel.


Fig. 2. Changing the stresses in the TiZrN coating on the front surface of the cutting tool over time: 1 - 0 min, 2,7 - 1 min, 3 - 5 min, 4 - 10 min, 5 - 5 s, 6 - $20 \mathrm{~s}$, a - MK8, b - P6M5K5, $x$ is the distance from the cutting edge 
The results of calculating the stresses $\sigma_{1}, \sigma_{\text {therm }}, \sigma_{\text {res }}, \sigma_{\Sigma}$ for the investigated coatings in the most dangerous zone (in the middle of the contact length of the chips with the front surface) are shown in Table. 1.

Table 1. Effect of the wear-resistant coating composition on its stress state

\begin{tabular}{|c|c|c|c|c|}
\hline Coating & $\sigma_{l}, \mathrm{MPa}$ & $\sigma_{\text {res }}, \mathrm{MPa}$ & $\sigma_{\text {therm }}, \mathrm{MPa}$ & $\sigma_{\Sigma}, \mathrm{MPa}$ \\
\hline \multicolumn{5}{|c|}{ Tool base - MK8 / Tool base - P6M5K5 } \\
\hline TiN & $546 / 1427$ & $-775 /-1501$ & $-1827 / 468$ & $-2056 / 394$ \\
\hline TiZrN & $613 / 1607$ & $-1256 /-2619$ & $-1906 / 484$ & $-2549 /-528$ \\
\hline TiZrAlN & $625 / 1651$ & $-1393 /-2953$ & $-2217 / 554$ & $-2985 /-748$ \\
\hline TiZrCrN & $609 / 1606$ & $-1413 /-2923$ & $-2132 / 542$ & $-2936 /-775$ \\
\hline
\end{tabular}

It can be seen that the composition of the coating also affects the stress values. So the lowest stresses are observed at the TiN coating. In the case of coating the carbide base, the stresses are compressive, and when deposited on high-speed steel, they are stretch-proof. Coatings of complex composition have higher values of compressive stresses. In this case, for all coatings, the influence of the tool base is similar to that discussed above. Coatings, doped simultaneously by two elements, have the greatest level of compressive stresses.

The effect of the wear-resistant coating composition on the change in the total stress $\sigma$ acting in the coating at the middle of the contact length of the chips with the front surface of the cutting tool over time is shown in Fig. 3. At the initial moment of time, the compressive stresses $\sigma$ (Fig. 3, a) act in the coating applied to the hard alloy, which, over time, under the influence of the creep of the tool base, they become compressive stresses. In this case, for the coating, TiZrN, the time for the transition of stresses from compressors to tensile forces increases by a factor of 1.4 in comparison with the TiN coating. For coatings of a more complex composition, the tool operating time before the appearance of tensile stresses in the coating increases by 4.6-7.4 times.
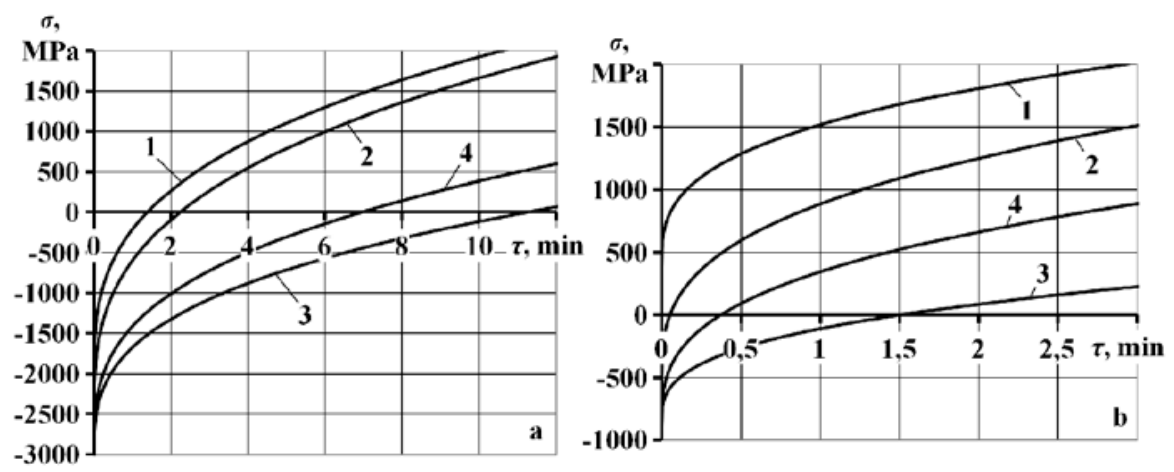

Fig. 3. Change in stresses in the coatings in the middle of the contact length of the chips with the front surface over time: 1 - TiN; 2-TiZrN; 3 - TiZrAlN; 4 - TiZrCrN; a - MK8; b-P6M5K5

For coatings applied to the tool base of high-speed steel, there is a somewhat different situation (Fig. 3, b). The formation of tensile total stress $\sigma$ in the coating occurs after a short work of the cutting tool. This is due to the fact that for coatings applied to high-speed steel, the compressive stresses acting in them are significantly less than the stresses in coatings on a carbide tool, and in some cases are generally tensile. For coatings of complex composition, the increase in the working time of the cutting tool prior to the appearance of tensile stresses in it is 20 to 80 seconds compared with the TiZrN coating.

Higher physical-mechanical properties of coatings of complex composition, the presence of large values of compressive stresses in them lead to an increase in the operating time before the tensile stresses appear in them and ensure the subsequent operation of the 
cutting tool at lower tensile stresses (Fig. 3). Such values of stresses in the material of coatings of complex composition lead to an increase in the working capacity of the cutting tool (Fig. 4).
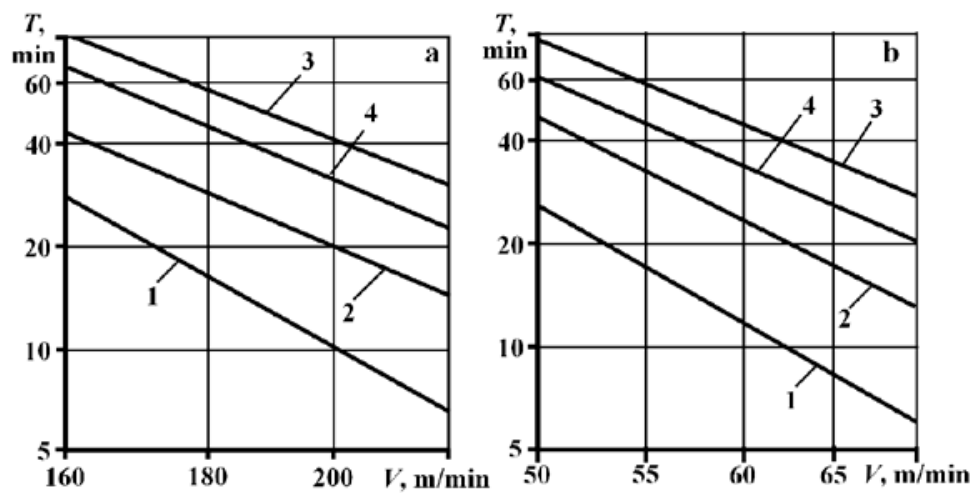

Fig. 4. Dependence of the period $T$ of the cutting tool with coatings on the cutting speed $V$ when turning workpieces from steel 30XГCA: 1 - TiN, 2 - TiZrN, 3 - TiZrAlN, 4 - TiZrCrN; a - MK8 b P6M5K5

Studies have established that the use of wear-resistant coatings makes it possible to increase the durability period of carbide-tipped plates by 2.3-4.6 times as compared with TiN coating, depending on the cutting speed. In this case, the greatest increase in the period of durability is provided by coatings of complex composition with high compressive stresses. For a tool made of P6M5K5 steel with coatings, a similar dependence is observed coatings with high compressive stresses provide the greatest increase in the period of durability. For a high-speed tool with TiZrAlN, TiZrCrN coating, the resistance, depending on the processing speed, increases by 2.4-4.5 times.

\section{Conclusion}

The tool base has an important influence on the formation of stresses in wear-resistant coatings. The difference in both the physical-mechanical properties of the coating and tool materials and the cutting conditions determine the influence on the stress components and their variation over time. At the same time, in the coatings deposited on the hard alloy, more favorable compressive stresses are created as compared to coatings applied to the high-speed substrate. In the course of the inevitable processes of creep of the tool material during the operation of the cutting tool in coatings applied to the hard alloy, the stresses are more compressive for a longer time, and in the future, when they become stretched, they have lower values. For coatings of complex composition, applied both to the hard alloy and to the fast-cutting steel, there are large values of the compressive stresses. A higher level of compressive stresses formed in the coating leads to an increase in the operability of the cutting tool.

\section{References}

1. B.Ya. Mokritskiy, Controlling the Efficiency of Tools by Means of Coating Application, (Upravleniye rabotosposobnostyu instrumenta pri nanesenii pokryty), STIN, 11, 11-15, (2010) 
2. M.A. Volosova, V.D. Gurin, Influence of vacuum-plasma nitride coatings on contact processes and a mechanism of wear of working surfaces of high-speed steel cutting tool at interrupted cutting, Journal of Friction and Wear, 34 (3), 183-189, (2013)

3. M. E. Maximov, Durable Coatings and Their Application to Improve the Performance of Cutters, (Iznosostoykiye pokrytiya $\mathrm{i}$ ikh primeneniye $\mathrm{V}$ povyshenii ekspluatatsionnykh kharakteristik rezhushchego instrumenta), Bulletin of the Moscow State Technical University MAMI, 4 (22), Vol. 2, 27-34, (2014)

4. V.N. Gadalov, V.G. Salnikov, D.N. Romanenko, I.V. Shirin, Durable Coatings for Cutters, (Iznosostoykiye pokrytiya dlya rezhushchego instrumenta), Mechanical Engineering Technology, (Tekhnologiya mashinostroyeniya), 7, 26-28, (2011)

5. A.S. Vereshchaka, A.A. Vereshchaka, A.I. Bulycheva, Multi-layer Nanodispersive Coatings for Cutters, (Mnogosloynye nanodispersnye pokrytiya dlya rezhushchego instrumenta), Strengthening Technologies and Coatings, (Uprochnyayushchiye tekhnologii i pokrytiya), 5, 33-39, (2014)

6. Y.G. Kabaldin, S.V. Seryi, S.N. Murav'ev, A.A. Prosolovich, E.V. Simagina, Improving cutter performance by the application of nanostructural coatings, Russian Engineering Research, 30 (3), 235-242, (2010)

7. V.P. Tabakov, A.V. Chikhranov, Multicomponent nitride coatings for improving tool performance, Russian Engineering Research, 29 (10), 1047-1053, (2009)

8. I.V. Blinkov, O.A. Volkhonskii, V.N. Anikin et al, Nanostructured wear-resistant coatings based on multicomponent nitrides and produced by vacuum-arc ion-plasma deposition, Protection of Metals and Physical Chemistry of Surfaces, 48 (6), 649-655, (2012)

9. V.P. Tabakov, A.V. Chikhranov, Selecting the composition of wear-resistant coatings, Russian Engineering Research, 38 (2), 105-109, (2018)

10. V.P. Tabakov, A.V. Chikhranov, Wear-Resistant Coatings of Cutting Tolls Operated in Continuous Cutting (Iznosostoikie pokrytiya rezhushchego instrumenta, rabotayushchego v usloviyakh nepreryvnogo rezaniya) (Ulyanovsk: Ulyanovsk Gos. Tekh. Univ., 2007)

11. S.S. Gorelik, L.N. Rastorguyev, Yu.A. Skakov, X-ray Structure and Electron-Optical Analysis of Metals, (Rentgenostrukturny i elektronnooptichesky analiz metallov), Metallurgizdat, (1970)

12. V.P. Tabakov, A.V. Chihranov, Determining the Mechanical Properties of Durable Ion Plasma Coatings Based on TiN, (Opredeleniye mekhanicheskikh kharakteristik iznosostoykikh ionno-plazmennykh pokryty na osnove nitrida titana), Bulletin of Samara RAS Research Center, 12 (4), 292-297, (2010)

13. A.D. Makarov, Optimization of cutting processes (Optimizatsiya protsessov rezaniya) (Moscow: Mashinostroenie, 1976)

14. A.N. Reznikov Thermophysics of processes of mechanical processing of metals (Teplofizika protsessov mekhanicheskoy obrabotki metallov) (Moscow: Mashinostroenie, 1981)

15. A.O. Volkhonskii, I.V. Blinkov, A.A. Vereshchaka, A.S. Vereshchaka, A.D. Batako, Filtered cathodic vacuum ARC deposition of nano-layered composite coatings for machining hard-to-cut materials, The International Journal of Advanced Manufacturing Technolog, 5-8 (84), 1647-1660, (2016)

16. A.S. Vereshchaka, Efficiency of Cutters with Durable Coatings, (Rabotosposobnost rezhushchego instrumenta s iznosostoykimi pokrytiyami), Mashinostroyeniye, (1993) 